\title{
One- versus two-stage partial hepatectomy for large resectable solitary hepatocellular carcinomas determined preoperatively to have a narrow resection margin: a propensity score matching analysis
}

\author{
Yao Li ${ }^{1 \#}$, Peng-Peng Li ${ }^{1 \#}$, Da-Peng Sun ${ }^{1 \#}$, Jun-Sheng $\mathrm{Ni}^{1 \#}$, Hui Liu ${ }^{1}$, Ze-Ya Pan ${ }^{1}$, Yuan Yang ${ }^{1}$, \\ Ling-Hao Zhao ${ }^{1}$, Wan Yee Lau ${ }^{1,2 *}$, Gang Huang ${ }^{1 *}$, Wei-Ping Zhou ${ }^{1,3,4 *}$ \\ ${ }^{1}$ The Third Department of Hepatic Surgery, Eastern Hepatobiliary Surgery Hospital, Shanghai, China; ${ }^{2}$ Faculty of Medicine, The Chinese \\ University of Hong Kong, Prince of Wales Hospital, Shatin, Hong Kong, China; ${ }^{3}$ Key Laboratory of Signaling Regulation and Targeting Therapy \\ of Liver Cancer (SMMU), Ministry of Education, Shanghai, China; ${ }^{4}$ Shanghai Key Laboratory of Hepatobiliary Tumor Biology (EHBH), Shanghai, \\ China \\ Contributions: (I) Conception and design: WY Lau, G Huang, WP Zhou; (II) Administrative support: WP Zhou; (III) Provision of study materials or \\ patients: JS Ni, H Liu, ZY Pan, Y Yang, LH Zhao; (IV) Collection and assembly of data: Y Li, PP Li, DP Sun; (V) Data analysis and interpretation: \\ Y Li, PP Li, DP Sun, JS Ni; (VI) Manuscript writing: All authors; (VII) Final approval of manuscript: All authors. \\ "These authors contributed equally to this work and should be considered as co-first authors. \\ *These authors contributed equally to this work. \\ Correspondence to: Wei-Ping Zhou, MD. Eastern Hepatobiliary Surgery Hospital, Second Military Medical University, 225 Changhai Rd., \\ Shanghai 200438, China. Email: ehphwp@126.com; Gang Huang, MD. Eastern Hepatobiliary Surgery Hospital, Second Military Medical \\ University, 225 Changhai Rd., Shanghai 200438, China. Email: squaror@163.com; Wan Yee Lau, MD, FRCS, FACS, FRACS (Hon). Faculty of \\ Medicine, The Chinese University of Hong Kong, Prince of Wales Hospital, Shatin, Hong Kong, China. Email: josephlau@cuhk.edu.hk.
}

Background: For patients with a large but resectable solitary hepatocellular carcinoma (HCC) of $>5 \mathrm{~cm}$ in diameter, it is often difficult to achieve a sufficient resection margin. There is still no study on whether a two-stage hepatectomy to increase a narrow resection margin would be beneficial.

Methods: From August 2014 to February 2017, patients with a large but resectable solitary HCC of $>5 \mathrm{~cm}$ and a preoperative estimated resection margin of $<1.0 \mathrm{~cm}$ were retrospectively studied. They were divided into one- and two-stage resection groups. A retrospective analysis was performed, followed by propensity score matching (PSM) analysis. Disease recurrence, survival, intraoperative and postoperative data were compared.

Results: Before PSM, the 1-, 2-, 3-and 4-year recurrence-free survival rates for the one- and two-stage groups were $44.3 \%, 31.7 \%, 24.3 \%, 19.2 \%$ versus $60.6 \%, 45.4 \%$, 43.5\%, 32.3\%, respectively $(\mathrm{P}=0.007)$. The corresponding OS rates were 61.0\%, 45.2\%, 43.8\%, 38.4\% versus 69.6\%, 62.5\%, 60.7\%, 57.3\%, respectively $(\mathrm{P}=0.029)$. After PSM, the 1-, 2-, 3-and 4-year recurrence-free survival rates for the one- and two-stage groups were 44.0\%, 31.5\%, 27.3\%, 21.0\% versus $60.6 \%, 45.4 \%, 43.5 \%, 32.3 \%$, respectively ( $\mathrm{P}=0.013)$. The corresponding OS rates were 62.5\%, 41.1\%, 41.1\%, 37.5\% versus 69.6\%, 62.5\%, 60.7\%, $57.3 \%$, respectively $(\mathrm{P}=0.038)$. Differences in the resection margins between the one- and two-stage groups before [0.3 $(0-0.5)$ versus $1.2(0.8-2.2) \mathrm{cm}]$ and after [0.2 $(0-0.5)$ versus $1.2(0.8-2.2) \mathrm{cm}]$ PSM were also significant.

Conclusions: Two-stage hepatectomy allowed a wider resection margin for patients with a resectable but solitary HCC of $>5 \mathrm{~cm}$, and resulted in significantly better long-term survival outcomes after partial hepatectomy.

Keywords: One-stage hepatectomy; two-stage hepatectomy; large solitary hepatocellular carcinoma (HCC); resection margin 
Submitted Sep 15, 2020. Accepted for publication Dec 09, 2020.

doi: $10.21037 /$ hbsn-20-711

View this article at: http://dx.doi.org/10.21037/hbsn-20-711

\section{Introduction}

The only treatments which can offer a potential of cure for patients with hepatocellular carcinoma (HCC) are partial hepatectomy, liver transplantation and radiofrequency ablation (1-3). For patients with a large $(>5 \mathrm{~cm})$, solitary but resectable HCC, most liver centers consider liver transplantation (4) and radiofrequency ablation (s) not to be the treatment options for cure (5), and partial hepatectomy is the remaining choice $(6,7)$. The Barcelona-Clinic Liver Cancer (BCLC) staging system recommends a solitary tumor with Child-Pugh of A-B to undergo liver resection $(8,9)$.

The three-dimensional computed tomographic (3D-CT) visualization technology of liver for preoperative planning of liver resection has been used to determine resection margins and volumes of future liver remnants to allow adequate but safe partial hepatectomy (10-12). In a patient with a solitary and large HCC, the amount of liver tissues that needs to be resected can be large. In a background of liver fibrosis/cirrhosis, post-hepatectomy liver function can be compromised. To ensure a sufficient volume of future liver remnant (FLR), a one-stage hepatectomy may have to be carried out with a narrow resection margin. The alternative is to use a two-stage hepatectomy to allow hypertrophy of the non-tumorous liver to increase the resection margin. There is still no consensus on which treatment option is better.

In HCC, the width of surgical resection margin is a known and important factor affecting long-term survival outcomes after liver resection (13-17). However, there is still no international consensus on the optimal range of resection margins. In the commonly used international guidelines, margins of $\geq 0.5-1 \mathrm{~cm}$ have been recommended (13,18-20).

The commonly used 2-stage hepatectomy to promote compensatory increase in FLR for patients with unresectable HCC include portal vein embolization (PVE), and associating liver partition and portal vein ligation for staged hepatectomy (ALPPS) (21-23).

The role of two-stage hepatectomy in patients who undergo one-stage hepatectomy with possibility of only achieving narrow resection margins has not been studied. The aim of the study was to compare the long-term survival outcomes of these patients who underwent one- or two-stage major hepatectomy and who were assessed preoperatively to have narrow resection margins for a solitary but large $\mathrm{HCC}$ of $>5 \mathrm{~cm}$ in diameter.

\section{Methods}

\section{Patients}

This is a retrospective, single-center study. From August 2014 to February 2017, consecutive patients who underwent major partial hepatectomy (resection of $>3$ Couinaud liver segments) for a large but resectable solitary HCC of $>5 \mathrm{~cm}$ in diameter and who were assessed by preoperative $3 \mathrm{D}$ CT visualization to have adequate volumes of FLR but narrow resection margins of $<1.0 \mathrm{~cm}$ entered into this study. It is known that a preoperatively planned width of resection margin might not be achieved on postoperative histopathological study of resected specimens. A detailed discussion was made between the operating surgeon and the patient to decide on the one- or two-stage approach for partial hepatectomy, resulting in two groups of patients in this study: the one-stage hepatectomy group, and the two-stage hepatectomy group. When patients decided to undergo a two-stage operation, further discussion was made on the merits and demerits of PVE versus ALPPS. The final decision was made with a consensus in opinions reached between the patient and the surgeon. The diagnosis of HCC and the determination of the actual resection margins were based on postoperative histopathological studies. The study was censored on May 31, 2019 and the follow-up periods for all the patients were $>24$ months, with a median follow-up of 36 months. All the operations were carried out with curative intent.

\section{Inclusion and exclusion criteria}

The inclusion criteria were patients: (I) aged 18 75 years, (II) who underwent 3D-CT visualization before surgery, with preoperative planning performed by a threedimensional visualization software, (III) who had a FLR volume which met the following requirements [FLR/ standard liver volume (SLV) $>30 \%$ in normal livers or $\geq 40 \%$ in cirrhosis], (IV) with an estimated preoperative resection 
margin $<1.0 \mathrm{~cm}$.

Cirrhosis was diagnosed based on any one of the following findings: (I) ultrasonic or other imaging examinations showing liver shrinkage, uneven surface, blunt liver edges, uneven liver parenchyma, and nodular shapes, (II) gastric/esophageal varices, (III) an inner diameter of portal vein greater than $13 \mathrm{~mm}$ and/or inner diameter of splenic vein greater than $8 \mathrm{~mm}$, (IV) thickness of splenic hilum greater than $4 \mathrm{~cm}$. The exclusion criteria were: (I) patients who refused to participate in this clinical trial, (II) hepatic dysfunction with a Child-Pugh score of Grade B or C, (III) portal hypertension, ascites, or any other serious extrahepatic complications of cirrhosis. We present the following article in accordance with the STROBE reporting checklist (available at https://hbsn.amegroups.com/article/ view/10.21037/hbsn-20-711/rc).

\section{Methods}

This study was conducted in accordance with the Declaration of Helsinki (as revised in 2013). The study was reviewed and approved by the Ethics Committee of Eastern Hepatobiliary Surgery Hospital. The Ethics Number is EHBHKY2014-03-019. All patients enrolled in this study signed an informed consent. This study was registered with the Chinese Clinical Trials Registry (ChiCTR) website and the Registration Number was ChiCTR-IOC-14005646.

\section{Propensity score matching (PSM)}

A propensity score was used to match the two groups of patients based on the results of the retrospective analysis to eliminate the impact of baseline differences on patient prognosis. The matched items included: main tumor diameter, microvascular invasion (MVI), age, gender, degree of liver fibrosis, and HBV-DNA levels. The matching was performed in a 1:1 ratio with a match tolerance of 0.1 .

\section{Three-dimensional visualization surgery planning and FLR calculation}

All patients underwent abdominal intravenous contrast enhanced CT scan using a GE 64-slice CT scanner before surgery with a layer thickness of $1.25 \mathrm{~mm}$. The data was stored in Digital Imaging and Communications in Medicine (DICOM) format. Either EDDA's IQQA or Shenzhen Xudong's three-dimensional visualization software was used for three-dimensional reconstruction and preoperative surgical planning. With participation of the operating surgeons and software technicians, resection was simulated according to the surgical plan, and the residual liver volume was calculated. The SLV calculation formula is: $\operatorname{SLV}(\mathrm{mL})=$ $706.2 \times \operatorname{BSA}\left(\mathrm{m}^{2}\right)+2.4(24)$.

\section{Surgical margin and bistological determination}

The surgical resection margin was defined as the minimum distance of normal liver parenchyma from the edge of tumor. Postoperative margins were obtained from experienced pathologists after surgery. The margin of preoperative planning was performed by surgeons and software technicians using the three-dimensional visualization computer software. R0 resection was defined as no residual tumor cells on histological examination of the liver resection edge. R1 resection was defined as presence of tumor cells on histological examination of the resection edge.

\section{Study design}

ALPPS was carried out using open surgery in the way as previously reported (25). PVE was conducted using embolization with Gelfoam particles with or without coils. The operative procedure was performed following the methods as previously reported (26). In brief, the process is as follows: the patient was placed in the supine position, anesthetized and disinfected, and a L-shaped incision of the abdomen was performed. A ultrasonic dissector was used to gradually transect the tumor-bearing liver from the remnant liver along a preoperatively planned plane. If necessary, surgical bleeding was controlled, and hepatic portal blood flow was blocked by Pringle's maneuver. The wound was cleaned after the tumor was removed, and the abdomen was closed. Transcatheter arterial chemoembolization (TACE) was conducted before PVE due to the long waiting time for liver enlargement to reach to adequate volumes of FLR after PVE. PVE was then carried out 2 weeks later when the liver function had returned to normal. During the waiting period, TACE was performed once every 4 weeks to control tumor growth. Sequential TACE and PVE is an established technique $(27,28)$. The use of Gelfoam particles to embolize part of the portal venous system allows recanalization and TACE to be repeated in patients with inadequate hypertrophy of FLR, followed by permanent embolization using coils (29). CT was performed once every week after the first stage of surgery. If the requirements of the margin 
of $>1.0 \mathrm{~cm}$ was met, surgical resection was performed, and if the requirement was not met, then CT scan was performed until the margin met the requirement, or until treatment failure occurred.

Treatment failure was defined as tumor progression resulting in unresectability, multiple intrahepatic or distant metastases of liver tumors, inadequate rate of enlargement of liver of less than $2 \%$ in a week, serious treatment complications or death.

\section{Study endpoints}

The primary end-points were overall survival (OS) and recurrence-free survival. Both OS and recurrence-free survival were counted from the day of surgical resection. Secondary end-points were intraoperative data and postoperative complications.

\section{Statistical analysis}

A propensity score for the two groups of patients was used to perform a $1: 1$ matching ratio with a tolerance of 0.1 . The matched items included: main tumor diameter, MVI, age, gender, degree of liver fibrosis, and HBV-DNA levels.

Continuous variables were expressed as median and range, and compared by the Mann-Whitney $U$ test. Categorical variables were expressed as numbers and ratios, and compared by the Chi-squared test or Fisher's exact test. OS was calculated from the date of liver resection until death or the last date of follow-up. Recurrence-free survival was calculated from the date of liver resection until the first HCC recurrence. OS and recurrence-free survival outcomes were calculated using the Kaplan-Meier method and compared using the Log-rank method. Univariate and multivariate analyses were performed using the Cox regression model with stepwise selection of variables. A $\mathrm{P}<0.05$ was considered statistically significant. Statistical analysis was performed using the Statistical Program for Social Sciences (SPSS 23.0 for Windows).

\section{Results}

\section{Comparison of baseline data and surgical margins in patients before matching}

During the study period, of 2,256 patients who underwent hepatectomy in our center, 202 patients satisfied the inclusion and exclusion criteria and were included into this study. There were 146 patients in the one-stage and 56 patients in the two-stage hepatectomy groups (ALPPS $=34$ and PVE =22). There were no significant differences between the baseline data of these two groups except in the resection margin: $0.3(0-0.5) \mathrm{cm}$ for the one-stage and $1.2(0.8-2.2) \mathrm{cm}$ for the two-stage hepatectomy groups $(\mathrm{P}<0.001)$, and in the resection type $(\mathrm{P}=0.008$; Table 1$)$. There were 17 patients with $\mathrm{R} 1$ resection, and they were all in the one-stage hepatectomy group. The 1-, 2-, 3-, and 4-year recurrence-free survival rates of $\mathrm{R} 0$ resection patients were $53.4 \%, 38.9 \%, 32.7 \%$, and $25.6 \%$, respectively. All $\mathrm{R} 1$ resection patients relapsed within one year of surgery, and $41.2 \%$ of patients relapsed within 6 months. The 1-, 2-, 3-, and 4-year OS for patients with R0 and R1 resections were $67.0 \%, 54.1 \%, 52.4 \%, 45.9 \%$ versus $17.6 \%, 5.9 \%$, $5.9 \%, 5.9 \%$, respectively $(\mathrm{P}<0.001)$. $\mathrm{R} 1$ resection resulted in significantly lower recurrence-free survival and OS outcomes. A preoperative planned wide surgical margin resulted in a significantly higher $\mathrm{R} 0$ resection rate.

The 1-, 2-, 3-, and 4-year recurrence-free survival rates in the one-stage and the two-stage hepatectomy groups were $44.3 \%, 31.7 \%, 24.3 \%, 19.2 \%$ versus $60.6 \%$, $45.4 \%$, $43.5 \%, 32.3 \%$, respectively $(\mathrm{P}=0.007$; Figure 1$)$.

The corresponding OS rates for the two groups were $61.0 \%, 45.2 \%, 43.8 \%, 38.4 \%$ versus $69.6 \%, 62.5 \%, 60.7 \%$, $57.3 \%$, respectively. The difference was again significant $(\mathrm{P}=0.029$; Figure 1).

The operation time, duration of hepatic vascular occlusion, and units of blood cell transfusion were significantly higher, but the amount of intraoperative bleeding were similar, and major postoperative complications $(\geq \mathrm{III}$ ) were significantly lower in the one-stage than the two-stage hepatectomy groups (Table 2). There were no significant differences in postoperative overall complications, post hepatectomy liver failure (PHLF), and postoperative 90-day mortality between the two groups (Table 3).

\section{Univariate and multivariate regression analyses of survival and recurrence}

Univariate analysis by the Cox regression model on age, gender, treatment grouping, main tumor diameter, MVI (+), HBV-DNA (>50 IU/mL), HBsAg (+), resection margin, resection type $(\mathrm{R} 1)$, degree of liver fibrosis, and alphafetoprotein $(>20 \mu \mathrm{g} / \mathrm{L})$ showed treatment grouping, main tumor diameter, MVI (+), HBV-DNA (>50 IU/mL), resection margin, $\mathrm{R} 1$ resection and degree of liver fibrosis to be significant factors for HCC recurrence. Treatment grouping, 
Table 1 Baseline characteristics of patients

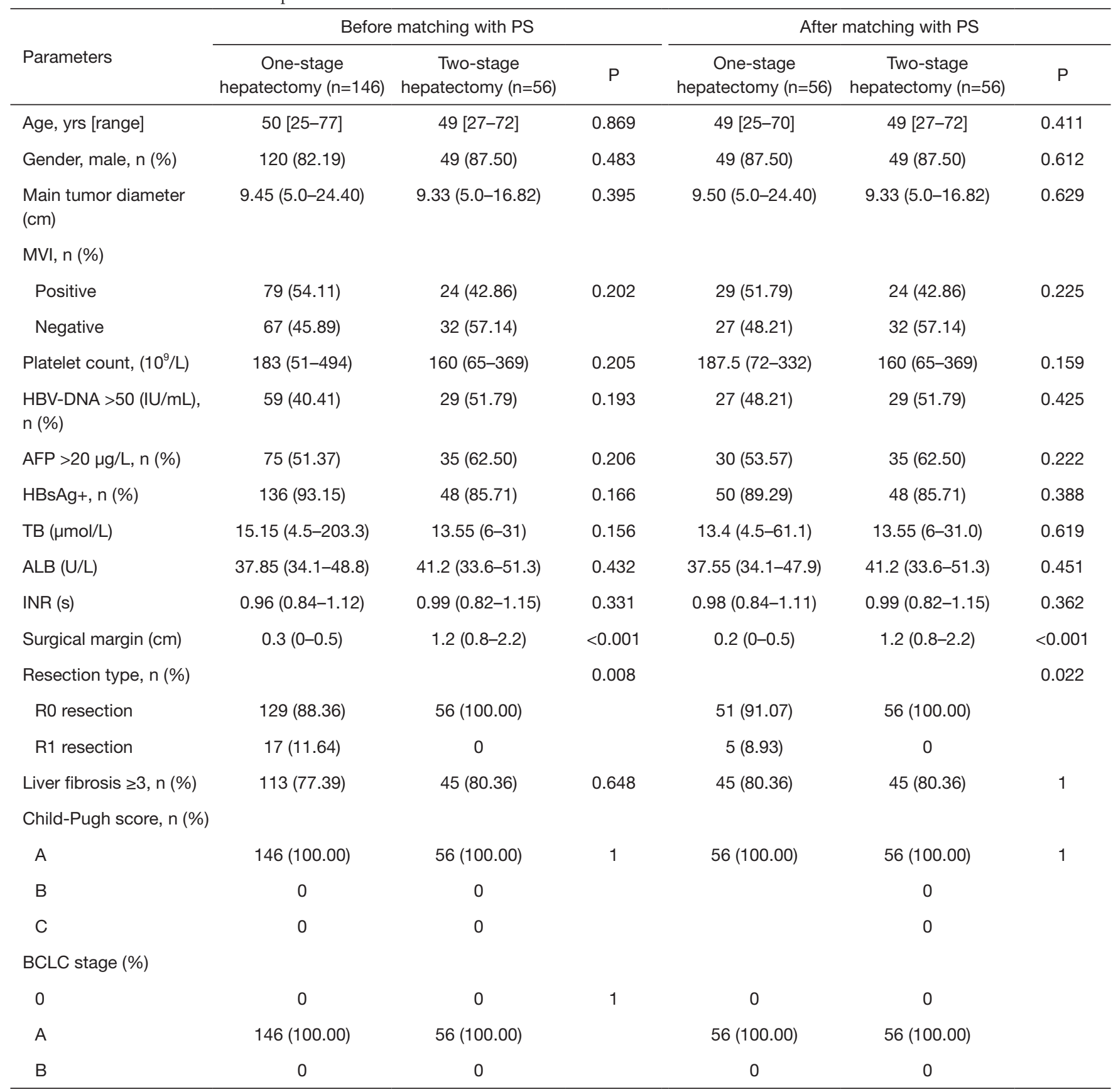

PS, propensity score; MVI, microvascular invasion; AFP, alpha-fetoprotein; HBsAg, hepatitis B surface antigen; TB, total bilirubin; ALB, albumin; INR, international normalized ratio; BCLC, Barcelona Clinic Liver Cancer classification.

main tumor diameter, MVI, HBV-DNA ( $>50 \mathrm{IU} / \mathrm{mL})$, resection margin, resection type (R1), degree of liver fibrosis, and alpha-fetoprotein $(>20 \mu \mathrm{g} / \mathrm{L})$ were significant factors for overall survival (Table 4).

Multivariate analysis showed resection margin, resection type (R1), main tumor diameter, and MVI to be significant risk factors for HCC recurrence. Resection margin, MVI, and $\mathrm{HBV}$-DNA $(>50 \mathrm{IU} / \mathrm{mL})$ were significant risk factors for OS. Thus, surgical margin was both a significant factor for HCC recurrence and overall survival $(\mathrm{P}=0.001, \mathrm{HR}$ 

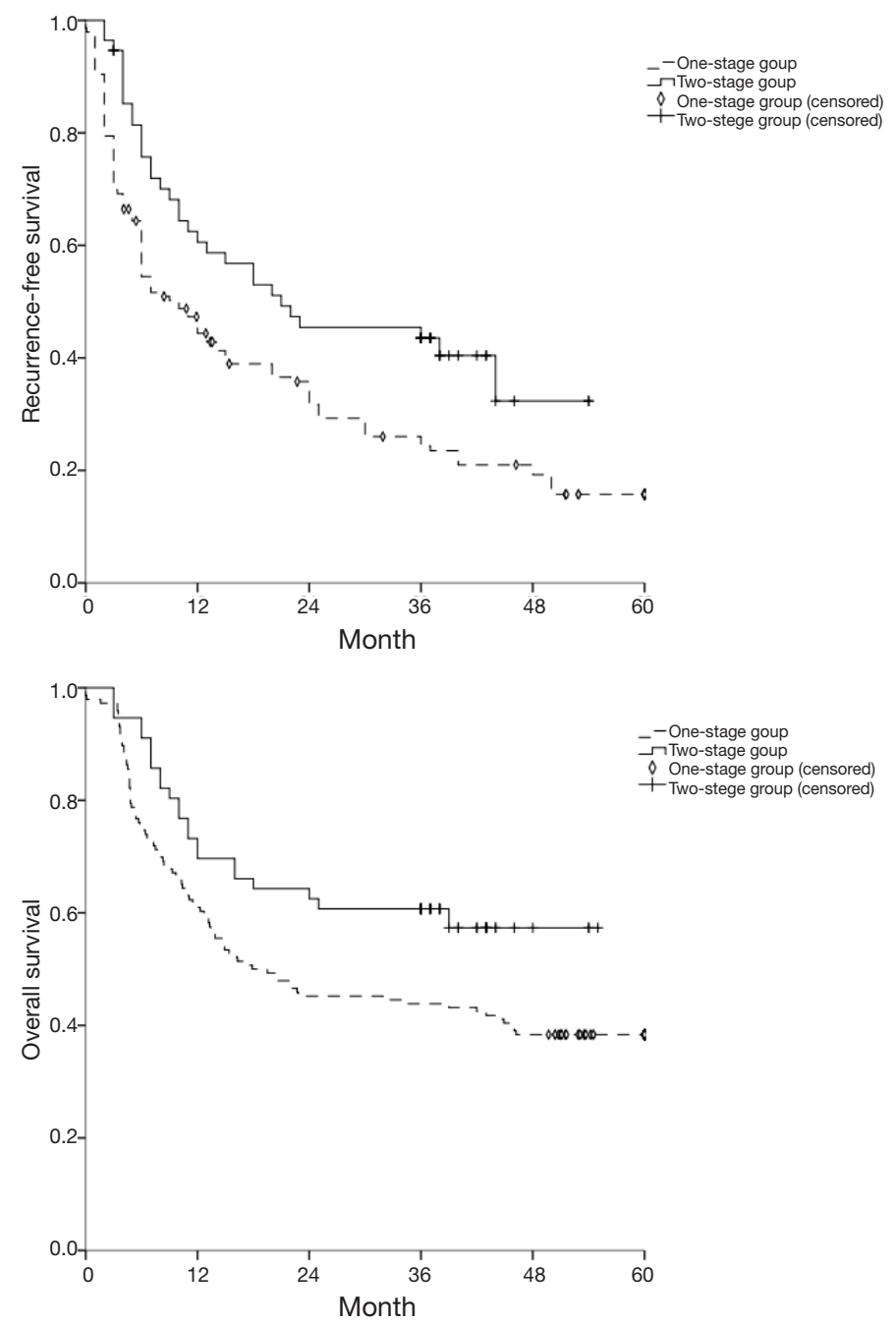

Figure 1 Comparison of recurrence-free survivals and overall survival between the 2 groups before matching $(\mathrm{P}=0.007$ and 0.029 , respectively, log-rank).

$=0.489,95 \%$ CI: $0.323-0.739 ; \mathrm{P}=0.002, \mathrm{HR}=0.455,95 \%$ CI: 0.275-0.755; Table 5). As treatment grouping was not a risk factor for both HCC recurrence and overall survival, its impact on long-term survival outcomes was mainly caused by the difference in resection margins between the two groups.

\section{Comparison of intraoperative data and postoperative complications between ALPPS and PVE}

The results of intraoperative and postoperative data of ALPPS and PVE in the two-stage hepatectomy group were compared. The results showed that the operation time and hepatic vascular occlusion time in the ALPPS group were significantly less, transfusion of blood cell units and intraoperative bleeding were similar, and incidence of major postoperative complications ( $\geq$ IIIa) was significantly higher than the PVE group (17 vs. 4). As the ALPPS patients were involved in two operative procedures, the baseline operation time of the second-stage hepatectomy was significantly less, but major complications were significantly more than one-stage hepatectomy (Table 2).

\section{Comparison of baseline data and resection margins in patients after PSM}

After PSM, there were 56 patients in each of the two groups 
Table 2 Comparison of intraoperative and postoperative data between ALPPS and PVE

\begin{tabular}{|c|c|c|c|}
\hline Parameters & ALPPS $(n=34)$ & PVE $(n=22)$ & $P$ \\
\hline Operation time (min) & $142.5(105-270)$ & $210(140-270)$ & $<0.001$ \\
\hline Pringle maneuver duration (min) & $11.5(0-22.0)$ & $21.0(0-44.0)$ & $<0.001$ \\
\hline Number of blood transfusion, $\mathrm{n}(\%)$ & $16(47.06)$ & $12(54.55)$ & 0.584 \\
\hline \multicolumn{4}{|l|}{ Type of hepatectomy, n (\%) } \\
\hline Right hepatectomy & $20(58.82)$ & $16(72.73)$ & \\
\hline Left hepatectomy & $2(5.88)$ & 0 & \\
\hline Right trisectionectomy & $8(23.53)$ & $6(27.27)$ & \\
\hline Major complications ( $\geq$ Illa), n (\%) & $17(50.00)$ & $4(18.18)$ & 0.034 \\
\hline Bile leakage + ascites + pleural effusion & 1 & 0 & \\
\hline Bile leakage + ascites & 1 & 0 & \\
\hline Atelectasis + intra-abdominal infection & 1 & 0 & \\
\hline Pleural effusion + hemorrhage & 3 & 0 & \\
\hline Pleural effusion + disruption of wound & 2 & 0 & \\
\hline Pleural effusion & 4 & 0 & \\
\hline Hemorrhage & 2 & 2 & \\
\hline Tumor progression & 0 & $1(4.55)$ & \\
\hline Hepatic dysfunction & $2(5.88)$ & $2(9.09)$ & \\
\hline
\end{tabular}

ALPPS, associating liver partition and portal vein ligation for staged hepatectomy; PVE, portal vein embolization.

of patients. There were no significant differences in the preoperative baseline data between the two groups (Table 1).

In the one-stage hepatectomy group, of $33(58.9 \%)$ patients who relapsed within 1 year, $20(35.7 \%)$ relapsed within 3 months. In the two-stage hepatectomy group, of $24(42.9 \%)$ patients who relapsed within one year, 6 (10.7\%) relapsed within 3 months. The median recurrence was 8 months in the one-stage hepatectomy group and 21 months in the two-stage hepatectomy group. After PSM, the recurrence-free survival rates of 1-, 2-, 3-, and 4-years in the one-stage hepatectomy group were $44.0 \%, 31.5 \%$, $27.3 \%$, and $21.0 \%$ versus the two-stage hepatectomy group of $60.6 \%, 45.4 \%, 43.5 \%$, and $32.3 \%$. The recurrencefree survival rates of the two-stage hepatectomy were significantly better than that of the one-stage hepatectomy group (Figure 2).

There were $23(41.1 \%)$ patients who survived for more than 3 years in the one-stage hepatecomy group and 
Table 3 Intraoperative and postoperative data of patients in the two groups

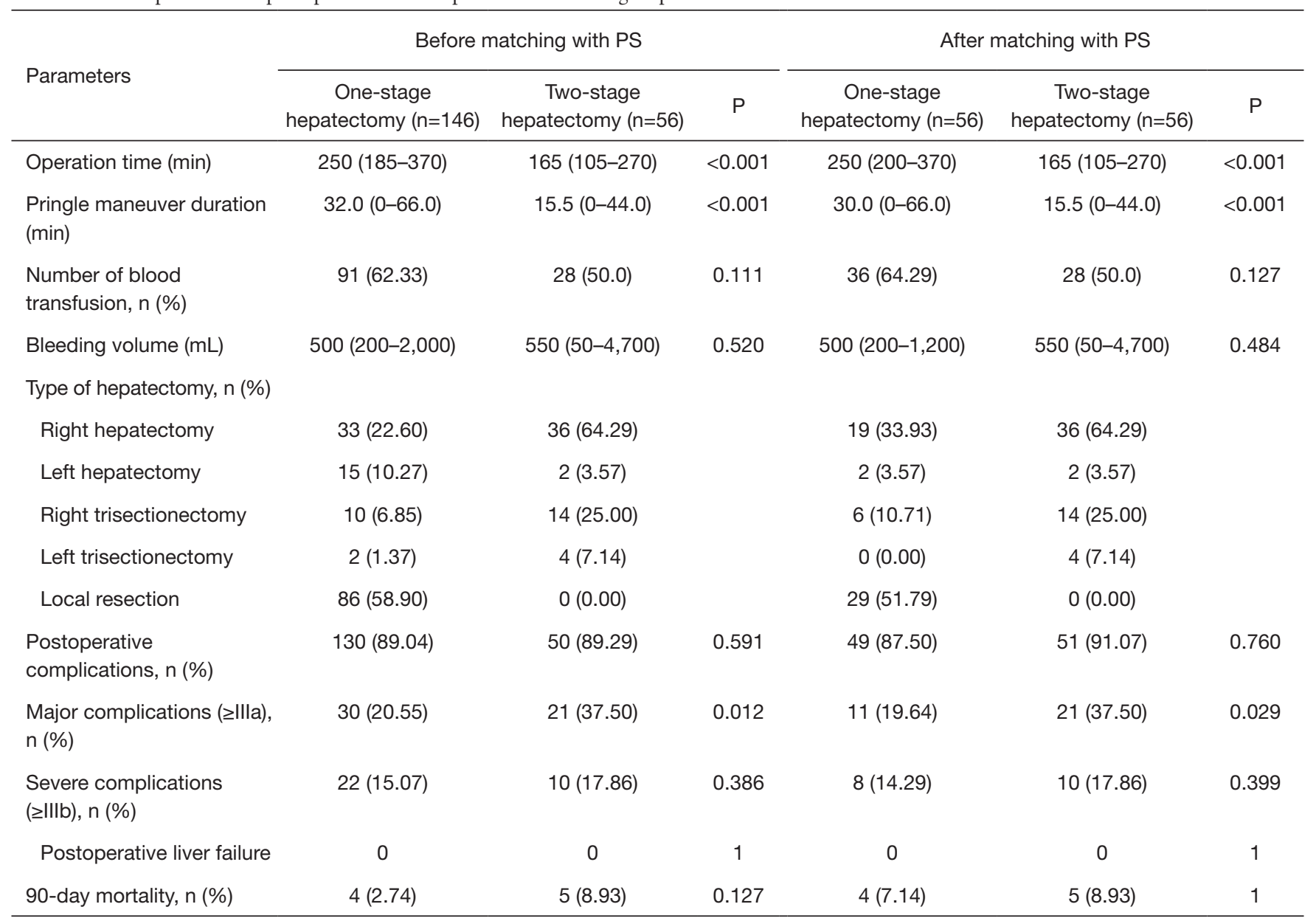

PS, propensity score.

$34(60.7 \%)$ in the two-stage hepatectomy group. After PSM, the 1-, 2-, 3-, and 4-year OS rates for the one-stage hepatectomy group were: $62.5 \%, 41.1 \%, 41.1 \%$, and $37.5 \%$ compared with the two-stage hepatectomy group of $69.6 \%$, $62.5 \%, 60.7 \%$, and $57.3 \%$. The OS rates of the two-stage hepatectomy were significantly better than the one-stage hepatectomy group (Figure 2).

There was significant difference in the width of resection margins between the two groups $(\mathrm{P}<0.01)$. The surgical margin $(\mathrm{cm})$ in the two-stage hepatectomy group was significantly greater than that of the one-stage hepatectomy, being $1.2(0.8-2.2)$ and $0.3(0-0.5) \mathrm{cm}$, respectively. The resection margins of the two-stage resection group were all $\geq 0.8 \mathrm{~cm}$, both before and after PSM (Table 1). However, for the one-stage hepatectomy group, the resection margins in some patients, both before and after PSM, could be as low as $0 \mathrm{~cm}$ ( $\mathrm{R} 1$ resection).

\section{Comparison of intraoperative data and postoperative complications in patients after PSM}

After PSM, the operation time and vascular hepatic occlusion time of the one-stage hepatectomy group were significantly longer, while intraoperative bleeding, postoperative overall complications (49 vs. 51), severe complications ( $8 v s .10)$, postoperative liver failure ( $0 v s .0)$, and postoperative 90 -day mortality (4 vs. 5) were similar, but the preoperative major complication rate $(\geq \mathrm{IIIa})$ was significantly less than the two-stage hepatectomy group (11 vs. 21, $\mathrm{P}=0.029$; Table 3).

\section{Discussion}

Two-stage hepatectomy has mainly been used in patients with unresectable liver cancer due to insufficient volumes of FLR to increase the resection rate. Whether the use of 
Table 4 Univariate regression analysis of recurrence and survival

\begin{tabular}{|c|c|c|c|c|}
\hline Factors & \multicolumn{2}{|c|}{ Recurrence } & \multicolumn{2}{|c|}{ OS } \\
\hline Age & $1.001(0.985-1.018)$ & 0.899 & 0.995 (0.977-1.014) & 0.621 \\
\hline Gender, male & $1.244(0.784-1.976)$ & 0.354 & $1.043(0.637-1.707)$ & 0.868 \\
\hline Group (1= one-stage) & $0.592(0.399-0.878)$ & 0.009 & $0.603(0.614-0.955)$ & 0.031 \\
\hline MVI (+) & $5.405(3.704-7.874)$ & $<0.001$ & $7.042(4.464-10.989)$ & $<0.001$ \\
\hline HBV-DNA >50 (IU/mL) & $1.727(1.247-2.392)$ & 0.001 & $1.992(1.374-2.890)$ & $<0.001$ \\
\hline Surgical margin & $0.547(0.372-0.805)$ & 0.002 & $0.508(0.314-0.819)$ & 0.006 \\
\hline Resection type (R1) & 4.469 (2.583-7.730) & $<0.001$ & 3.253 (1.887-5.609) & $<0.001$ \\
\hline
\end{tabular}

OS, overall survival; MVI, microvascular invasion; AFP, alpha-fetoprotein.

Table 5 Multivariate regression analysis of recurrence and survival

\begin{tabular}{|c|c|c|c|c|}
\hline Factors & \multicolumn{2}{|c|}{ Recurrence } & \multicolumn{2}{|l|}{ os } \\
\hline Surgical margin & $0.489(0.323-0.739)$ & 0.001 & $0.455(0.275-0.755)$ & 0.002 \\
\hline Resection type (R1) & $2.473(1.413-4.327)$ & 0.002 & & \\
\hline Main tumor diameter & $1.052(1.013-1.093)$ & 0.009 & & \\
\hline HBV-DNA >50 (IU/mL) & & & 1.493 (1.022-2.179) & 0.038 \\
\hline
\end{tabular}

OS, overall survival; MVI, microvascular invasion.

two-stage hepatectomy to allow a more adequate resection margin is more beneficial than a one-stage hepatectomy has not been reported. Our study suggested that a wider surgical margin is important in influencing long-term survival outcomes in patients with a solitary $\mathrm{HCC}$ of $>5 \mathrm{~cm}$ in diameter.

The resection margin in liver resection refers to the minimum distance of tumor from non-tumorous tissues. Liver resection can be divided into $\mathrm{R} 0, \mathrm{R} 1$, and $\mathrm{R} 2$ resections. However, there is currently no consensus on how much this distance needs to be to differentiate between $\mathrm{R} 0$ and R1 resections. Our research shows that the R0 resection rate $(100 \%)$ of the two-stage hepatectomy group after extending the resection margin was higher than the one-stage hepatectomy group $(88.36 \%)$. At the same time, patients with $\mathrm{R} 0$ resection had better recurrence-free survival and OS than those with $\mathrm{R} 1$ resection. In major liver resection, a balance between safety and surgical margin is important. While it is necessary to conserve as much functioning liver parenchyma as possible, an adequate resection margin to achieve R0 resection is also important. Even when histopathology shows R0 resection, recurrence of HCC has been shown to associate with micrometastasis which can be present outside of the resection margin if the resected marginal width is too narrow. The width of resection margin for HCC is still controversial (18). Previous studies and guidelines recommend a resection margin which varies from 0.5 to $2 \mathrm{~cm}(24-26,30,31)$. These studies and guidelines, however, all agree that an adequate resection margin to achieve $\mathrm{R} 0$ resection is important in reducing recurrence and prolonging long-term survival outcomes of patients. Our study showed that in patients 

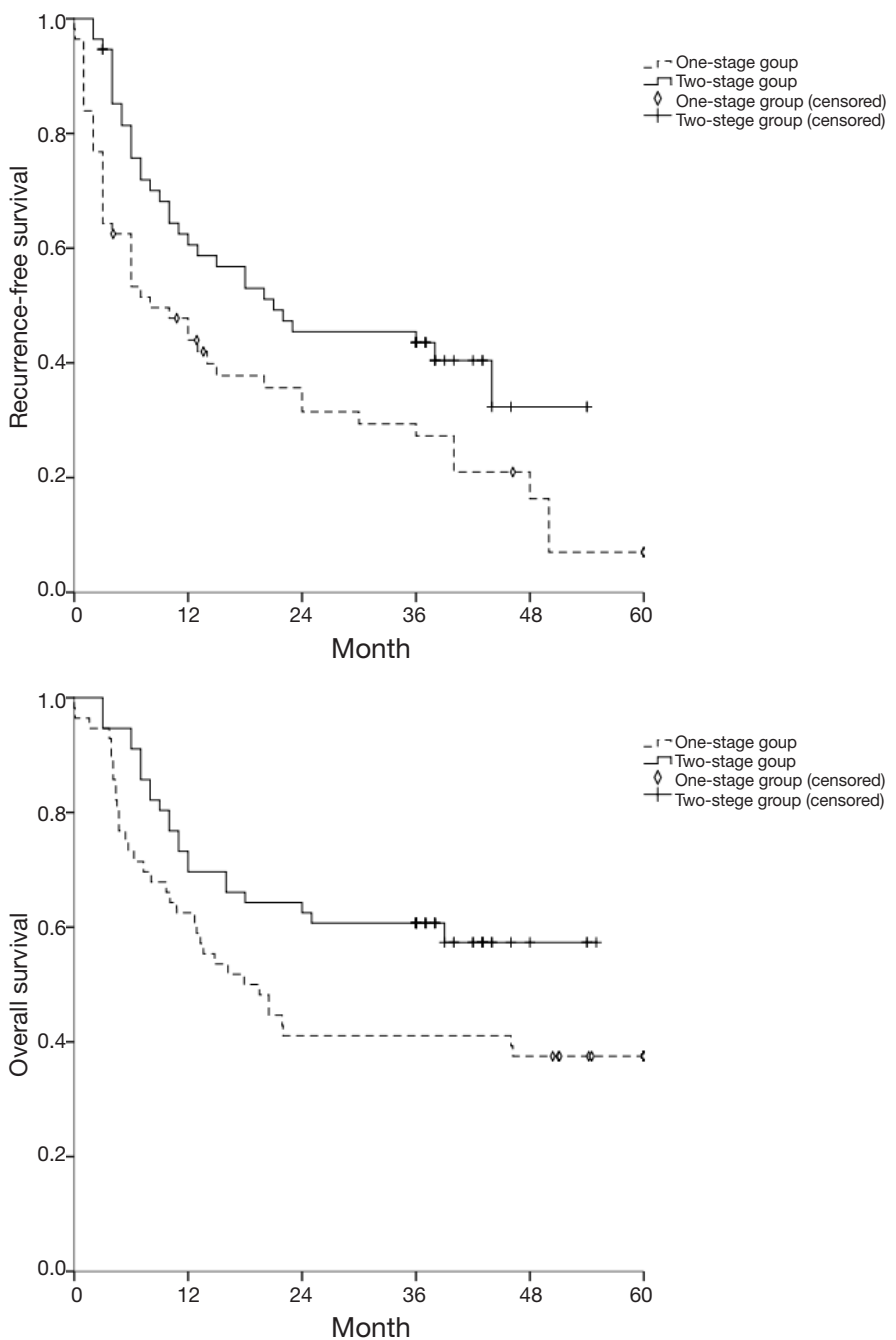

Figure 2 Comparison of recurrence-free survivals and overall survival between the 2 groups after matching $(\mathrm{P}=0.013$ and 0.038 , respectively, log-rank).

who were assessed preoperatively to have a narrow resection margin, two-stage hepatectomy could improve the resection margin with resultant improvement in recurrence-free and OS outcomes.

To enable adequate volumes of FLR after major hepatectomy, two-stage hepatectomy using PVE or ALPPS has been commonly used. PVE blocks the portal venous blood flow to the part of the liver containing the tumor, resulting in compensatory hyperplasia of the remaining liver. This was first used by Makuuchi in the treatment of intrahepatic cholangiocarcinoma (32). On the other hand, ALPPS is performed by two stages of surgery. In surgery stage I, the portal supply to the part of liver to be resected is disconnected and the plane between the parts of the liver to be resected or preserved is made. In surgery stage II, surgical resection is performed after adequate hyperplasia of FLR. ALPPS can rapidly increase the volume of FLR (33-35). Further developments in two-stage hepatectomy include the use of PVE combined with TACE to decrease tumor growth during the waiting time for increase in volume of FLR (36). Advances in PVE materials to improve regeneration speed of FLR and improvement in surgical experience result in decline of postoperative complications of ALPPS (30-33). In our study, the increased volumes of FLR allowed wider resection margins in the 2-stage hepatectomy.

Three-dimensional visualization technology allows surgeons to simulate surgical resection in preoperative surgical planning, to accurately calculate volumes of FLR, 
and to predetermine and assess resection margins. This technology has been shown to improve safety of surgery and it is useful in surgical planning (10). In this study, three-dimensional visualization technology allowed us to determine liver regeneration in two-stage hepatectomy, and to extend resection margins, thus finally improving the $\mathrm{R} 0$ surgical resection rate, reduced postoperative liver failure, and improved long-term survival outcomes of patients.

The limitations of this study are: first, this is a retrospective study with its inherent defects. Second, this study did not use current advances in PVE materials, such as NBCA and microspheres (34-36) which can result in faster liver hyperplasia rates. Third, this is a single center study. The results may not be applied in other centers. Fourth, this study was designed as a retrospective study which aimed to compare long-term survival outcomes in patients who underwent one- or two-stage major hepatectomy and who were assessed preoperatively to have narrow resection margins for a solitary but large HCC $>5 \mathrm{~cm}$ in diameter. This study was not designed to study treatment failure, disease progression in between stages for two-stage hepatectomy and it was not based on intentionto-treat analysis. As a consequence, biases can be introduced and further prospective studies need to be conducted to clarify these points.

In conclusion, this study suggested that resection margins affected recurrence and prognosis of patients with a solitary HCC of $>5 \mathrm{~cm}$ in diameter after major hepatectomy. Twostage hepatectomy extended the resection margins in these patients. Preoperative three-dimensional visualization reconstruction and surgical simulation were important in determining volumes of FLR and surgical resection margins.

\section{Acknowledgments}

Funding: This study was supported by: Science Fund for Creative Research Groups, NSFC, China (81521091); State Key Infection Disease Project of China (2018ZX10732202002-005); Shanghai Rising Star Program (20QA1412000); National Natural Science Foundation of China (81702734); Natural Science Foundation of Shanghai Municipal Commission of Health and Family Planning (Y20170006, 2017Y0109).

\section{Footnote}

Reporting Checklist: The authors have completed the STROBE reporting checklist. Available at https://hbsn. amegroups.com/article/view/10.21037/hbsn-20-711/rc

Data Sharing Statement: Available at https://hbsn.amegroups. com/article/view/10.21037/hbsn-20-711/dss

Conflicts of Interest: All authors have completed the ICMJE uniform disclosure form (available at https://hbsn. amegroups.com/article/view/10.21037/hbsn-20-711/coif). WYL serves as an unpaid editorial board member of Hepatobiliary Surgery and Nutrition. The other authors have no conflicts of interest to declare.

Ethical Statement: The authors are accountable for all aspects of the work in ensuring that questions related to the accuracy or integrity of any part of the work are appropriately investigated and resolved. The study was conducted in accordance with the Declaration of Helsinki (as revised in 2013). This study was reviewed and approved by the Ethics Committee of Eastern Hepatobiliary Surgery Hospital. The Ethics Number is EHBHKY2014-03-019. All patients enrolled in this study signed an informed consent. This study was registered with the Chinese Clinical Trials Registry (ChiCTR) website and the Registration Number was ChiCTR-IOC-14005646.

Open Access Statement: This is an Open Access article distributed in accordance with the Creative Commons Attribution-NonCommercial-NoDerivs 4.0 International License (CC BY-NC-ND 4.0), which permits the noncommercial replication and distribution of the article with the strict proviso that no changes or edits are made and the original work is properly cited (including links to both the formal publication through the relevant DOI and the license). See: https://creativecommons.org/licenses/by-nc-nd/4.0/.

\section{References}

1. Vogel A, Cervantes A, Chau I, et al. Hepatocellular carcinoma: ESMO Clinical Practice Guidelines for diagnosis, treatment and follow-up. Ann Oncol 2018;29:iv238-55.

2. Marrero JA, Kulik LM, Sirlin CB, et al. Diagnosis, Staging, and Management of Hepatocellular Carcinoma: 2018 Practice Guidance by the American Association for the Study of Liver Diseases. Hepatology 2018;68:723-50.

3. Heimbach JK, Kulik LM, Finn RS, et al. AASLD guidelines for the treatment of hepatocellular carcinoma. Hepatology 2018;67:358-80. 
4. Mazzaferro V, Regalia E, Doci R, et al. Liver transplantation for the treatment of small hepatocellular carcinomas in patients with cirrhosis. N Engl J Med 1996;334:693-9.

5. N'Kontchou G, Mahamoudi A, Aout M, et al. Radiofrequency ablation of hepatocellular carcinoma: long-term results and prognostic factors in 235 Western patients with cirrhosis. Hepatology 2009;50:1475-83.

6. Yamashita Y, Taketomi A, Shirabe K, et al. Outcomes of hepatic resection for huge hepatocellular carcinoma $(>/=$ $10 \mathrm{~cm}$ in diameter). J Surg Oncol 2011;104:292-8.

7. Min YW, Lee JH, Gwak GY, et al. Long-term survival after surgical resection for huge hepatocellular carcinoma: comparison with transarterial chemoembolization after propensity score matching. J Gastroenterol Hepatol 2014;29:1043-8.

8. Forner A, Reig M, Bruix J. Hepatocellular carcinoma. Lancet 2018;391:1301-14.

9. Bruix J, Sherman M, Llovet JM, et al. Clinical management of hepatocellular carcinoma. Conclusions of the Barcelona-2000 EASL conference. European Association for the Study of the Liver. J Hepatol 2001;35:421-30.

10. Li PP, Wang ZH, Huang G, et al. Application of liver three-dimensional visualization technologies in the treatment planning of hepatic malignant tumor. Zhonghua Wai Ke Za Zhi 2017;55:916-22.

11. Li P, Wang M, Yang Y, et al. Preoperative threedimensional versus two-dimensional evaluation in assessment of patients undergoing major liver resection for hepatocellular carcinoma: a propensity score matching study. Ann Transl Med 2020;8:182.

12. Chengxi Li and Andrew Zhu. Application of Image Fusion in Diagnosis and Treatment of Liver Cancer. Appl Sci 2020;10:1171.

13. Margonis GA, Sergentanis TN, Ntanasis-Stathopoulos I, et al. Impact of Surgical Margin Width on Recurrence and Overall Survival Following R0 Hepatic Resection of Colorectal Metastases: A Systematic Review and Metaanalysis. Ann Surg 2018;267:1047-55.

14. Ma KW, Chok KSH. Importance of surgical margin in the outcomes of hepatocholangiocarcinoma. World J Hepatol 2017;9:635-41.

15. Nagasue N, Uchida M, Makino $Y$, et al. Incidence and factors associated with intrahepatic recurrence following resection of hepatocellular carcinoma. Gastroenterology 1993;105:488-94.

16. Lise M, Bacchetti S, Da Pian P, et al. Prognostic factors affecting long term outcome after liver resection for hepatocellular carcinoma: results in a series of 100 Italian patients. Cancer 1998;82:1028-36.

17. Ikai I, Arii S, Kojiro M, et al. Reevaluation of prognostic factors for survival after liver resection in patients with hepatocellular carcinoma in a Japanese nationwide survey. Cancer 2004;101:796-802.

18. Jarnagin W, Chapman WC, Curley S, et al. Surgical treatment of hepatocellular carcinoma: expert consensus statement. HPB (Oxford) 2010;12:302-10.

19. Lazzara C, Navarra G, Lazzara S, et al. Does the margin width influence recurrence rate in liver surgery for hepatocellular carcinoma smaller than $5 \mathrm{~cm}$ ? Eur Rev Med Pharmacol Sci 2017;21:523-9.

20. Shi M, Guo R, Lin X, et al. Partial hepatectomy with wide versus narrow resection margin for solitary hepatocellular carcinoma: a prospective randomized trial. Ann Surg 2007;245:36-43.

21. Giglio MC, Giakoustidis A, Draz A, et al. Oncological Outcomes of Major Liver Resection Following Portal Vein Embolization: A Systematic Review and Meta-analysis. Ann Surg Oncol 2016;23:3709-17.

22. Marti J, Giacca M, Alshebeeb K, et al. Analysis of Preoperative Portal Vein Embolization Outcomes in Patients with Hepatocellular Carcinoma: A Single-Center Experience. J Vasc Interv Radiol 2018;29:920-6.

23. Mizuno T, Cloyd J, Omichi K, et al. Two-Stage Hepatectomy vs One-Stage Major Hepatectomy with Contralateral Resection or Ablation for Advanced Bilobar Colorectal Liver Metastases. J Am Coll Surg 2018;226:825-34

24. Urata K, Kawasaki S, Matsunami H, et al. Calculation of child and adult standard liver volume for liver transplantation. Hepatology (Baltimore, Md.) 1995;21:1317-21

25. Narita M, Oussoultzoglou E, Ikai I, et al. Right portal vein ligation combined with in situ splitting induces rapid left lateral liver lobe hypertrophy enabling 2-staged extended right hepatic resection in small-for-size settings. Ann Surg 2012;256:e7-8; author reply e16-7.

26. Azoulay D, Castaing D, Krissat J, et al. Percutaneous portal vein embolization increases the feasibility and safety of major liver resection for hepatocellular carcinoma in injured liver. Ann Surg 2000;232:665-72.

27. Goumard C, Komatsu S, Brustia R, et al. Technical feasibility and safety of laparoscopic right hepatectomy for hepatocellular carcinoma following sequential TACEPVE: a comparative study. Surg Endosc 2017;31:2340-9

28. Tustumi F, Ernani L, Coelho FF, et al. Preoperative 
strategies to improve resectability for hepatocellular carcinoma: a systematic review and meta-analysis. HPB (Oxford) 2018;20:1109-18.

29. Lesurtel M, Belghiti J. Temporary portal vein embolization as a starter of liver regeneration. J Hepatol 2008;49:313-5

30. Schnitzbauer AA, Lang SA, Goessmann H, et al. Right portal vein ligation combined with in situ splitting induces rapid left lateral liver lobe hypertrophy enabling 2-staged extended right hepatic resection in small-for-size settings. Ann Surg 2012;255:405-14.

31. Schadde E, Raptis DA, Schnitzbauer AA, et al. Prediction of Mortality After ALPPS Stage-1: An Analysis of 320 Patients From the International ALPPS Registry. Ann Surg 2015;262:780-5; discussion 785-6.

32. Linecker M, Stavrou GA, Oldhafer KJ, et al. The ALPPS Risk Score: Avoiding Futile Use of ALPPS. Ann Surg 2016;264:763-71.

33. Nadalin S, Capobianco I, Li J, et al. Indications and limits

Cite this article as: Li Y, Li PP, Sun DP, Ni JS, Liu H, Pan ZY, Yang Y, Zhao LH, Lau WY, Huang G, Zhou WP. One- versus two-stage partial hepatectomy for large resectable solitary hepatocellular carcinomas determined preoperatively to have a narrow resection margin: a propensity score matching analysis. HepatoBiliary Surg Nutr 2022;11(5):662-674. doi: 10.21037/ hbsn-20-711 for associating liver partition and portal vein ligation for staged hepatectomy (ALPPS). Lessons Learned from 15 cases at a single centre. Z Gastroenterol 2014;52:35-42.

34. Luz JHM, Luz PM, Bilhim T, Martin HS, et al. Portal vein embolization with n-butyl-cyanoacrylate through an ipsilateral approach before major hepatectomy: single center analysis of 50 consecutive patients. Cancer Imaging 2017;17:25.

35. Wajswol E, Jazmati T, Contractor S, et al. Portal Vein Embolization Utilizing N-Butyl Cyanoacrylate for Contralateral Lobe Hypertrophy Prior to Liver Resection: A Systematic Review and Meta-Analysis. Cardiovasc Intervent Radiol 2018;41:1302-12.

36. Geisel D, Malinowski M, Powerski MJ, et al. Improved hypertrophy of future remnant liver after portal vein embolization with plugs, coils and particles. Cardiovasc Intervent Radiol 2014;37:1251-8. 